\title{
Panel Description: Are the Organisations' IT competence the LIMITING factor?
}

\author{
Panel Chair: \\ Nils Hфeg,Corporate Staff for Information Systems \\ Norsk Hydro a.s ,Oslo, Norway
}

Panel Participants:

Dr. Espen Andersen, Foundation Research Program CSC Research and Advisory Services, Cambridge, Mass., USA.

\section{POSITION STATEMENT FROM PANEL CHAIR}

With due respect to IFIP and it's name, from a pragmatic user industry point of view, it is only the last five to ten years that the computers have evolved into "information machines". The advent and proliferation of the $\mathrm{PC}$, and the merging with the gradually deregulated communication world, has really given new meaning to the concept and realisation of "information systems". In numbers, the networked PCs are racing to catch up with that other info-machine, the telephone, of which there are about 1000 millions worldwide. Just as the telephone had significant organisational effects, so will the PC/IT-networks, with information machines that are potentially 10-100 times as powerful.

As we all know, the telephones (or most of them) are very easy to operate and use. Gradually, over several decades, the telephone services have become better and cheaper, and available to practically everyone working in organisations with information or communication needs. Managers and workers of practically all categories understand the potential function and role of the telephone, in day to day operation, in new approaches to e.g. marketing, and as an obvious resource when organising activities, whether locally, nationally or across the world.

Not so with the PC/networked info-machines. They have been thrust upon individuals and organisations at an unprecedented pace during half a decade, often by vendors and other pushers who don't understand the vital processes they are influencing. The hype is scoring even at the highest offices, and investments in individual $\mathrm{HW}$ and $\mathrm{SW}$ tools are passing all previous records.

While the present hype is vast, so are the potential benefits of the wired organisation and society. We who pretend to understand at least part of the larger picture should ask ourselves: 
Which are the critical success factors for the realisation of these benefits, and the utilisation of the enormous material and human resources involved?

Of the many factors that constitute today's and tomorrow's information architectures, it seems that most of the focus is on the material end: information highways, bandwidths, ISDN, faster/better/cheaper hardware, better/smarter/cheaper software and methods, etc. These are all objects of investments and ROI, sales and profits, and grants and funds for research and development. These are all healthy drivers in our marketdriven economies, which function very well in the information industries and markets. We certainly want deregulated and nondominated markets, and we are almost there. Thus, I don't see any truly limiting factors ind the material IT-arena. Some countries and regions may have competitive disadvantages, but in the large, world (IFIP-type) picture : We have and will have more than enough of material IT-resources available.

BUT, will we have the human resources available, with the knowledge, understanding and skills ( $=3 \mathrm{D}$ competence) to utilise the vast offerings of $=$ IT ? Or are we forced to drink from a fire hydrant?

The simple and plain position of mine is that IT-competence is the limiting factor for our utilisation and application of IT. This applies to practically all organisations, and particularly to decentralised organisations, where many more individuals and organisational units will influence and further develop the information systems.

The lack of IT-competence is not within the IT-communities. The overwhelming challenge is to provide all influencing participants in the present and future workforce with the necessary IT-competence (knowledge, understanding and skills). Influencing participants are those employees which in a large or small way influence the way in which organisations are organised. Traditionally strictly in the realm of managers, in the (near) future organisations all participants should understand the objectives and processes, and influence by contributing to improvements as part of the job. The necessary IT-competence to do this will of course vary with organisational position and role, but I venture to state that all employees in future, successful organisations need to have a considerable IT-competence compared with today, in order to function well and to be comfortable in their work environment.

\section{SUGGESTED ISSUES FOR PANEL DISCUSSION}

Can we (quickly) agree that IT-competence, among the users, could be a limiting factor, or at least one of a few critical factors, for the successful development, use and improving of distributed information systems?

If so, could we discuss the role of the IT- professionals in alleviating this situation (e.g. by understanding more about what goes on in business and other $=20$ organisations).

We should also present and discuss approaches to defining and realising the necessary ITcompetence levels for the users, at the base level (like the Finnish Computer Driving Licence), at the management level, and for other professions. 